\title{
4. SEDIMENT DEPTHS DETERMINED BY COMPARISONS OF GRAPE AND LOGGING DENSITY DATA DURING LEG $138^{1}$
}

\author{
S. Harris, ${ }^{2}$ T. Hagelberg, ${ }^{2,3}$ A. Mix, ${ }^{2}$ N.G. Pisias, ${ }^{2}$ and N.J. Shackleton ${ }^{4}$
}

\begin{abstract}
Establishing true depths of recovered sediments is critical to determining sedimentation rates for high-resolution paleoclimatic studies. We have corrected the composite depth scale, which accounts for the entire continuous sedimentary sequence, so that sediment depths are consistent with logging depths, or "true" depths. We accomplished this by taking advantage of dual measurements of sediment density: in-situ wireline density logs and shipboard Gamma-Ray Attenuation Porosity Evaluator (GRAPE) density measurements. Inverse correlation techniques (Martinson et al., 1982) were used to map the composite GRAPE density record to the logging density record at five sites (Sites $846,847,849,850$, and 851). Using these mapping functions, depths on the meters composite depth scale (mcd) were transformed to logging depths, which were then used to calculate sedimentation rates and discrete sample depths. Tables are provided for converting med to logging depth (see CD-ROM, this volume). Our analysis shows that the GRAPE and density logging data are coherent at wavelengths longer than $80 \mathrm{~cm}$. This analysis indicates that logging records are good references for establishing true depth scales in sedimentary sections and may be successful proxies for shipboard measurements over sections having incomplete or poor core recovery, within some limitations. To estimate density variability over such sections, we define an average gain function for the logging tool that can be used to scale logging data to account for the tool's attenuation. Using the med to logging depth transformations, age models developed from cores can be applied accurately to logging data.
\end{abstract}

\section{INTRODUCTION}

In this study, we demonstrate a method to express the most complete sedimentary record on the most accurate depth scale. We correlated two independent measurements of sediment density made during Leg 138: density measured in whole cores by the GRAPE, and density measured in the borehole by the high-temperature lithodensity tool (HLDT). We assumed that the GRAPE wet-bulk density measurements represent the most complete and high-resolution density records available and that the HLDT measurements represent the variation of sediment density at the closest approximation to true sediment depths. Together, these two density measurements allow us to place highresolution sediment data into a framework consistent with borehole measurements and "true" depths. After our correlations, we estimated the attenuation of the logging density data and investigated the effects of changing sedimentation rates on the logging and GRAPE records.

\section{Composite Sections}

ODP drilling recovers sediment cores from each hole sequentially in approximately $9.5-\mathrm{m}$ sections. Although the advanced-piston-corer (APC) and extended-core-barrel (XCB) coring devices often recover complete cores of relatively undisturbed sediment, parts of the sedimentary section often are missing. Gaps are often present at breaks between successive cores (Shackleton and Hall, 1983; Heath et al., 1985; Ruddiman et al.,1987; Farrell and Janecek, 1991) and, occasionally, successive cores overlap sections. To assure documentation of the most complete sedimentary sequence, records from multiple, adjacent holes at a single site must be combined to create a composite section.

${ }^{1}$ Pisias, N.G., Mayer, L.A., Janecek, T.R., Palmer-Julson, A., and van Andel, T.H. (Eds.), 1995. Proc. ODP, Sci. Results, 138: College Station, TX (Ocean Drilling Program).

College of Oceanic and Atmospheric Sciences, Oregon State University, Ocean Admin. 104, Corvallis, OR 97331-5503, U.S.A.

${ }^{3}$ Now at Graduate School of Oceanography, University of Rhode Island, Narragansett, RI 02882, U.S.A.

${ }^{4}$ Subdepartment of Quaternary Research, The Godwin Laboratory, Cambridge University, Cambridge, United Kingdom.
Such composite sections have been constructed for deep-sea sites from several DSDP and ODP cruises using several different types of data. Sediment color, percentage of $\mathrm{CaCO}_{3}$, magnetic susceptibility (Ruddiman et al., 1987; deMenocal et al., 1991; Murray and Prell, 1991; Farrell and Janecek, 1991; Alexandrovitch and Hays, 1989; Karlin et al., 1989; Bloemendal et al., 1988; Robinson, 1990; Froelich et al., 1991), oxygen isotope (Shackleton and Hall, 1989), and coarse fraction data (Farrell and Janecek, 1991) have all been used to correlate between holes at one drilling site (a summary of all previous compositing efforts is given in Hagelberg et al., this volume). Previous to Leg 138 , researchers observed that composite sections are $7 \%$ to $10 \%$ longer than depths in meters below seafloor (mbsf; Shackleton et al., 1990; deMenocal et al., 1991; Farrell and Janecek, 1991). Froelich et al. (1991) and Farrell and Janecek (1991) recognized that borehole logs provide a means of reconciling composite depths with true depths. In this study, we take a similar approach to resolve discrepancies between sediment composite depths and borehole depths.

\section{Leg 138}

At each Leg 138 site, data from three or more adjacent holes were correlated to construct complete composite sections (Hagelberg et al., 1992). As is standard practice, recovered cores were assigned mbsf depths based on the length of the drill string. At sea, it was discovered that data expressed on the mbsf depth scale did not correlate well between adjacent holes at each site.

Three independent data sets were used to construct composite sections: GRAPE, magnetic susceptibility, and digital reflectance, which were measured aboard the ship on almost all cores at intervals ranging from 1 to $5 \mathrm{~cm}$. To correlate data from adjacent holes, whole cores (which are usually about $9.5 \mathrm{~m}$ in length) were translated along the depth scale so that sedimentary features in all three data sets common to all overlapping sections in adjacent holes were aligned. These adjustments consisted of a constant added or subtracted to mbsf depths. The depth scale defined by these translations is the meters composite depth (mcd) scale. Different constants were applied to each core, depending on the extent of translation necessary to correlate between adjacent holes. The resulting composites have proven accurate for hole-to-hole correlations of stable isotope records (Mix et al., 
a, this volume; Mix et al., b, this volume), which supports the composite's robustness. Additional detail and examples regarding composite section development are provided by Hagelberg et al. (1992) and Hagelberg et al. (this volume).

In most cases, depth adjustments used for forming the composite depth section involved addition of a positive constant to the mbsf depth. Positive adjustments led to the "growth" of composite section depths noted by shipboard scientists, as the offsets used to transform mbsf depths to mcd depths also increase with depth. Hagelberg et al. (1992) noted that the total lengths of composite depth sections from Leg 138 sites are at least $10 \%$ longer than the cored intervals, which is of similar magnitude to observations made during previous ODP legs (Legs 111, $115,117,121)$. The cause of the $10 \%$ discrepancy between the mbsf and mcd scales is not fully understood. Some extra length results from expansion of the sediment as pressure is removed from overburden (MacKillop et al., this volume). In addition, the coring process also must expand the section, because often $10 \mathrm{~m}$ or more is recovered in a single core when the core barrel only advanced $9.5 \mathrm{~m}$ (Hagelberg et al., 1992). At the same time, the composite record shows that gaps are present between cores and that less than $90 \%$ of the sequence is actually recovered from a single hole. The result is that although composite sections document continuity of the entire sedimentary section, the mcd scale does not reflect true depth below the seafloor.

Development of a composite depth section including data from every hole at a site allowed Shackleton et al. (1992) to assemble a single, spliced GRAPE record from each site. These "shipboard splices" were constructed by linking together representative data among adjacent holes, switching from hole to hole at points where the GRAPE data overlap perfectly. Data used for these splices are given in CD-ROM form in the Initial Reports volume of Leg 138 (Mayer, Pisias, Janecek, et al., 1992). Tie points for the splices are also given in Table 1 of Hagelberg et al. (this volume). The shipboard splices were used as a reference signal for subsequent modifications of the mcd scale (Hagelberg et al., this volume). Revisions established a common composite depth scale (revised mcd, or rmcd) for all holes at each site. The revisions correct for relative distortion within individual cores, which causes local deviations from the splice. Such distortion may be an artifact of the coring process or may reflect local sedimentation variability among holes. For the core intervals that define the shipboard splices, rmcd equals mcd. Any true distortion in the original shipboard splice remains in the rmcd scale.

We assume that GRAPE data from the composite sections and the shipboard splices are the most complete density record from Leg 138 sites. They document continuous density variations without gaps in the record between successive cores. Whenever possible, we used these data in our comparisons to logging records instead of using an incomplete record from only one hole at each site. Two notable exceptions are Site 850 below $75 \mathrm{~m}$ and Site 846 below $250 \mathrm{~m}$, where the section was not multiple cored.

\section{Core-log Correlations}

In the Initial Reports volume of Leg 138, Hagelberg et al. (1992) compared composite GRAPE density with logging density data, illustrating the similarity between the two measurements. This comparison showed that much of the first-order distortion in the composite depth sections can be accounted for by a simple linear compression of the mcd scale. The potential of core-to-log comparisons using inverse correlation, a nonlinear correlation technique, was demonstrated in site chapter summaries of the Initial Reports volume (Mayer, Pisias, Janecek, et al., 1992) and by Lyle et al. (1992). Variability on the order of 2 to $3 \mathrm{~m}$ (common to both the GRAPE and log data sets) was observed. Here, we use inverse correlation techniques (Martinson et al., 1982) and demonstrate that even smaller-scale features are coherent between sediment- and log-measured densities. We present data that reconciles the complete sections from Leg 138 sites with the true depth scale that was recorded by borehole logs.
Figure 1 shows the locations of the five sites studied (846, 847, 849,850 , and 851 ). We chose these sites to satisfy two criteria: (1) that the site is in a carbonate-dominated depositional environment and (2) that the site was logged.

\section{METHODS}

Bulk density of recovered cores was measured by the GRAPE. This instrument measures gamma-ray attenuation through unsplit cores, which then is compared to the attenuation through an aluminum standard (Boyce, 1976). GRAPE measurements were taken continuously as each core advanced on the multisensor track, and these were averaged over $1.0-\mathrm{cm}$ sampling intervals. The composite GRAPE sections were constructed from GRAPE data that had been smoothed to a resolution of approximately $2 \mathrm{~cm}$ with a $6-\mathrm{cm}$ Gaussian filter. Over most of the APC-cored sections (the upper sections of each hole, corresponding to about the top 4 m.y.), GRAPE data from all holes at each site were averaged to reduce the signal-to-noise ratio and to produce a single GRAPE record for each site (Hagelberg et al., this volume). Figure 2 shows the extent of the stacked records for each site and the depth at which drillers switched from APC- to XCB-coring. For most of Site 846, we used stacked GRAPE records (three holes stacked) on the rmcd scale (Hagelberg et al., this volume). For the bottom of Site 846 and for Sites $847,849,850$, and 851 , we used composite GRAPE records defined by the shipboard splices (Shackleton, 1992) where stacked records were not available.

The HLDT tool was used to measure borehole density during Leg 138. This tool measures electron density from Compton scattering of gamma rays emitted by a $0.66 \mathrm{MeV}{ }^{137} \mathrm{Ce}$ gamma-ray source (Schlumberger, 1989). Electron density is then converted to bulk density with reference to an empirical calibration in a freshwaterfilled limestone formation of known electron and bulk density. The HLDT records measurements every 15 to $20 \mathrm{~cm}$, but has a sampling window of about $50 \mathrm{~cm}$ that smooths small-scale features in the sedimentary record. The smoothing function is approximated by a three-point moving average (D. Ellis, pers. comm., 1993).

The logging depth scale is established by the length of logging wire extended during measurement. Most error in this depth scale is the result of ship's heave, which would distort true depths (Ruddiman, 1985). The ship's heave compensator removes the effects of most

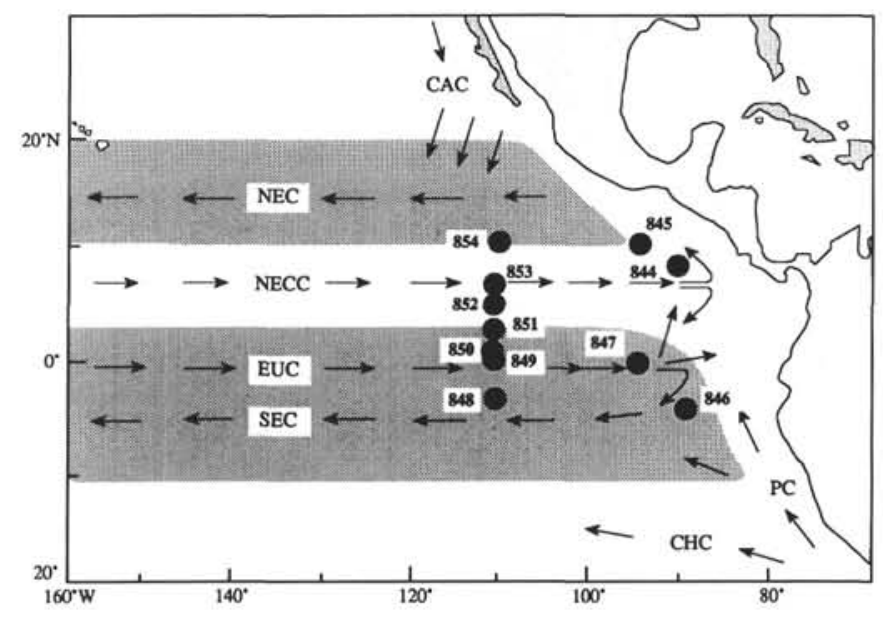

Figure 1. Leg 138 site locations and general circulation system of the eastern equatorial Pacific. Sites studied $(846,847,849,850$, and 851$)$ are represented by filled circles. Surface current shown as solid arrows, subsurface current shown as dashed arrows. $\mathrm{CAC}=$ California Current; $\mathrm{NEC}=$ North Equatorial Current; NECC $=$ North Equatorial Countercurrent; EUC $=$ Equatorial Undercurrent; $\mathrm{SEC}=$ South Equatorial Current $; \mathrm{PC}=$ Peru Current; and $\mathrm{CHC}=$ Chile Current. Shaded areas illustrate general latitudinal extent of the SEC and NEC. 


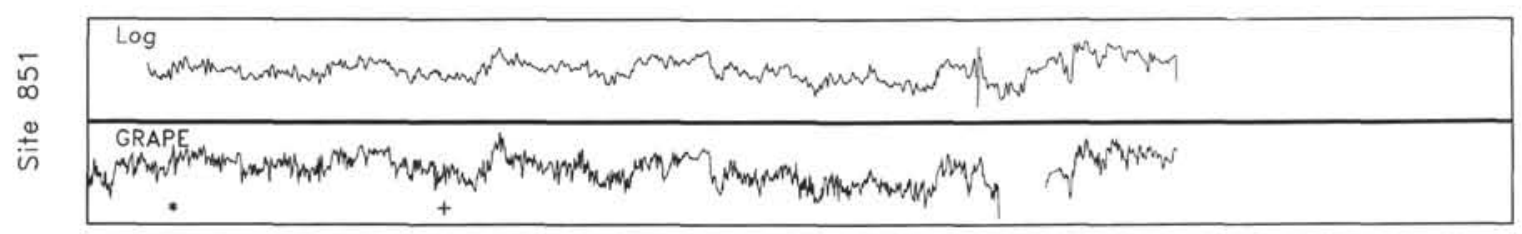

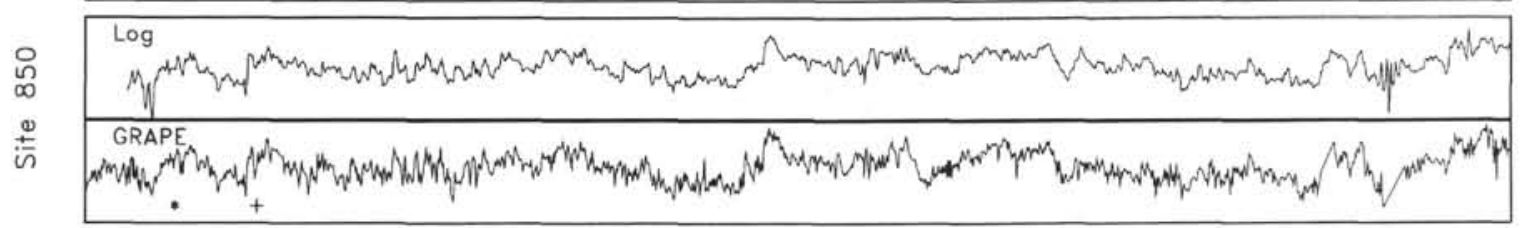

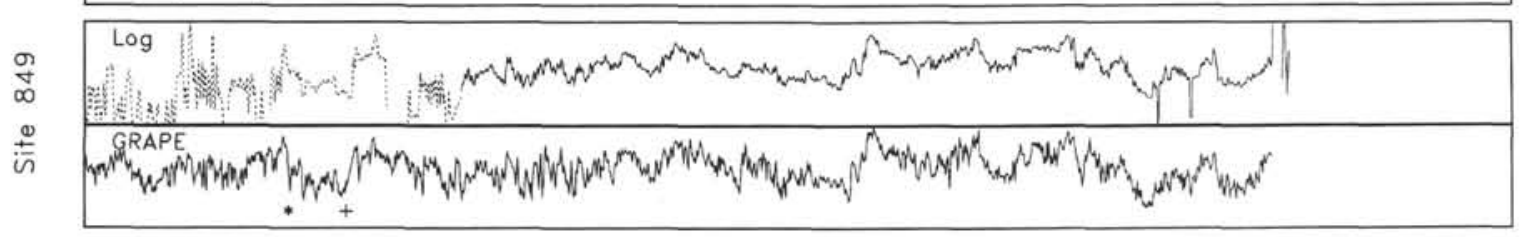

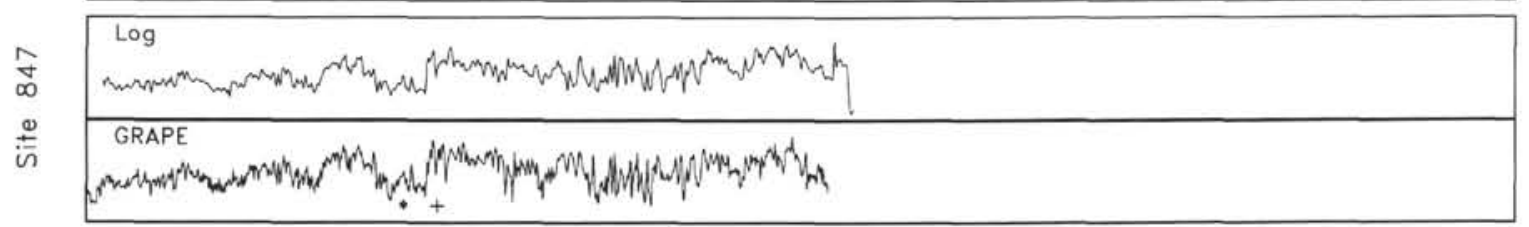

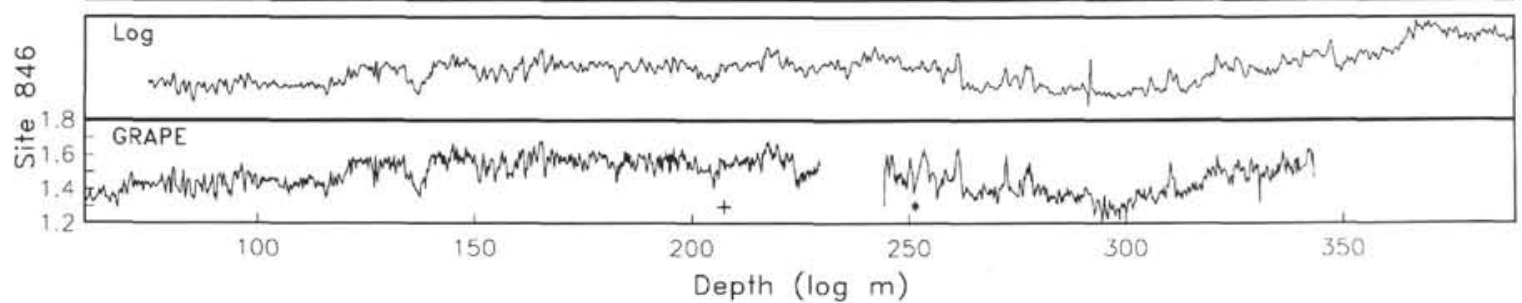

Figure 2. Comparison of GRAPE with logging density records after mapping. Note match of density features between GRAPE and log data within a site. The dashed portion of the logging record of Site 849 indicates the section where a nonlinear correlation between the records was not performed because of the poor quality of logging data. $(*)$ marks the depth to which stacked GRAPE records are available. (+) marks the depth at which drillers switched from APC- to XCB-coring.

heave during logging. At Sites 846 and 847 , the heave compensator was operating. It was not working during logging at Sites 849,850 and 851 , although the sea surface was calm, with swells below $1 \mathrm{~m}$ (Mayer, Pisias, Janecek, et al., 1992). Any distortion resulting from ship's heave remains in the logging records. Although imperfect, we assume that depths measured by the logging tool are the most true of any available and use this scale as our reference.

GRAPE data and logging data were correlated using inverse correlation techniques (Martinson et al., 1982). Inverse correlation matches a "distorted" signal (sediment records measured by GRAPE) to a reference signal (borehole logs) by defining a Fourier mapping function that translates one depth scale to another. Obtaining realistic depth translations using inverse correlation is somewhat subjective. Factors affecting the outcome are (1) accuracy of the initial guess, (2) number of Fourier coefficients used, and (3) length of the record to be correlated. The user selects the number of Fourier coefficients, which controls the number of harmonic sine waves used in the mapping function. Choosing the appropriate number of Fourier coefficients to use is not straightforward. Although high correlation coefficients can be obtained with many Fourier coefficients and much stretching and squeezing, these mapping functions have sharp discontinuities and are unrealistic. We have chosen the number of Fourier coefficients that maximize correlations, while avoiding abrupt and drastic changes to the continuity of the GRAPE records and to the slopes of the mapping functions. The number of Fourier coefficients used here ranges from 5 to 19. Each correlation was stopped when improvement in the correlation coefficient was insignificant $(<0.01)$, or when the addition of extra Fourier coefficients caused unrealistic changes to the slope of the mapping function.

Inverse correlation is most successful when the two signals are of similar resolution. This is because the correct "first guess" of the mapping function relies on matching maxima and minima between two records. If the number of local maxima and minima in the two records is comparable, the probability of making the best first guess is enhanced. Resolution of GRAPE density data is much higher than that of log density data because the logging tool smooths information over a broader sampling window. Composite GRAPE sampling intervals are typically about $2 \mathrm{~cm}$, while the log sampling intervals are 15 to $20 \mathrm{~cm}$. These differences in sampling interval make direct comparisons from shipboard splices to logging records difficult.

To overcome this resolution mismatch, we interpolated the composite GRAPE records to a sampling interval of $15 \mathrm{~cm}$, while smoothing with a $45-\mathrm{cm}$ Gaussian filter. This procedure reduced the amplitude of variations in GRAPE with wavelengths less than $45 \mathrm{~cm}$ and almost completely removed variations with wavelengths less than about $25 \mathrm{~cm}$. Smoothing degraded the GRAPE data to approximately, although slightly higher than, the resolution of the logs, which allowed us to use the inverse correlation technique. These GRAPE data (at $15-\mathrm{cm}$ intervals) are the data we used to map med to log meters. Henceforth, the term "GRAPE" refers to these smoothed data unless otherwise indicated.

The first step in mapping the two data sets was to make an initial guess (by eye). We chose distinct features in the two density records that were easily correlated (for example, see Fig. 3, points $p$ and $q$ ). 

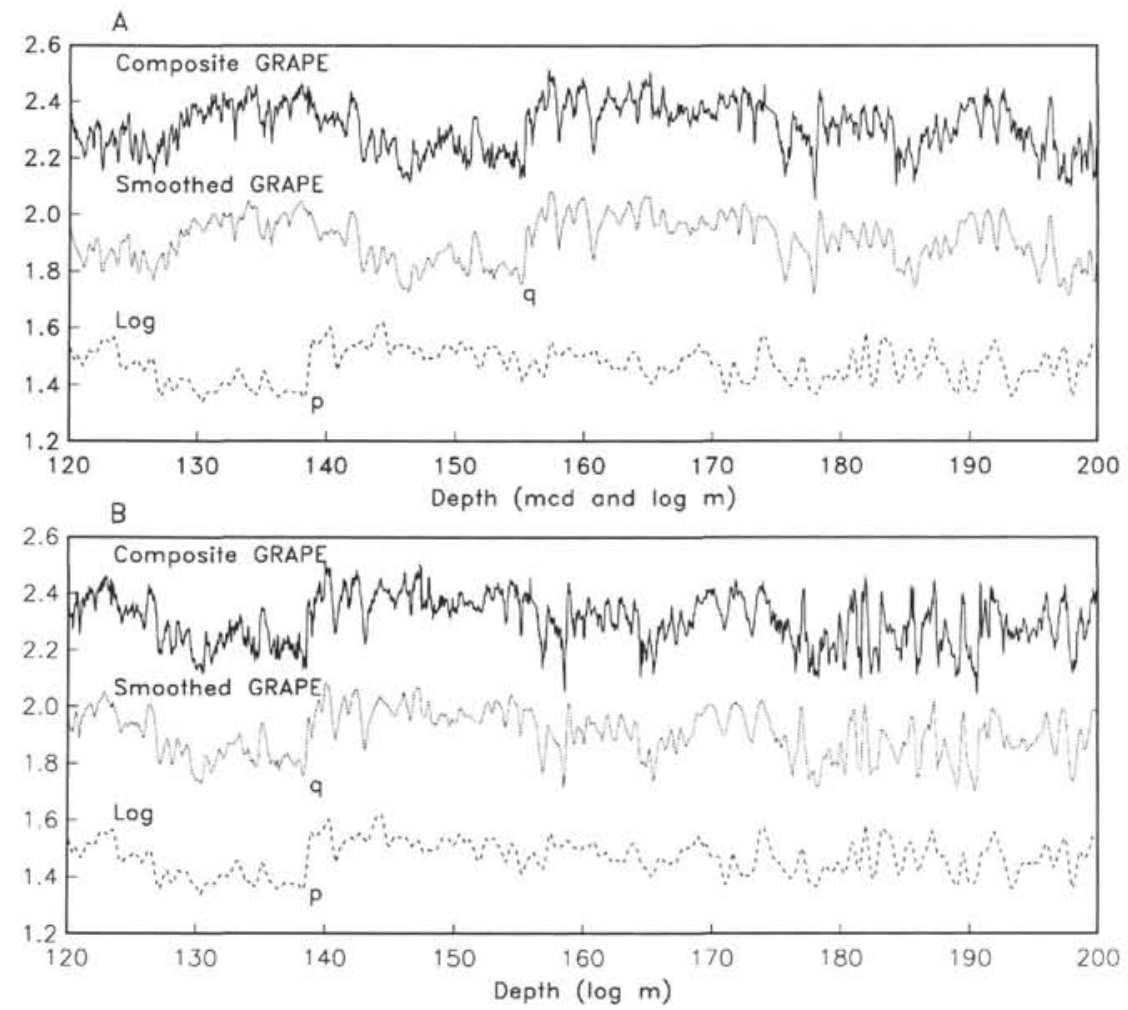

Figure 3. Segment from Site 847 comparing composite GRAPE, smoothed GRAPE, and logging data before and after the application of the new depth transformation from mcd to log meters. A. Composite GRAPE, smoothed GRAPE, and logging data on their respective original scales (mcd for the two GRAPE signals, log meters for the log) before any mapping. At this depth, GRAPE data on the mcd scale are more than $15 \mathrm{~m}$ longer than the reference logging record. Note offset of distinctive density minimum at points $p(\mathrm{log})$ and $q$ (GRAPE). B. Reconciliation of GRAPE data to logging depth scale. Point $q$ has been matched to point $p$. Maps were determined by matching smoothed GRAPE to the logging signal. Note differences in resolution of the three records. Offset for convenience.

Initial tie points were evident as maxima and minima that were spaced from 70 to $150 \mathrm{~m}$ apart. These served to shorten linearly the GRAPE data to the total length of the log meter scale and to match prominent features. Results of the initial "squeezing," with first-order features matched, served as a base for further fine-scale modifications using inverse correlation. This first step serves merely as a convenience to enable one to map small-scale features more accurately. Subsequent fine-scale correlations in segments of 5 to $60 \mathrm{~m}$ in length produced continuous mapping functions that translate mcd depths to logging depths. Correlations were optimized while discontinuities in the mapping functions were minimized.

Matching the GRAPE and logging density data is possible only where a logging record is available. Density logging records typically begin at about $75 \mathrm{mbsf}$, where the hole is stable enough to be left unlined (Fig. 2). Above this depth, we adjusted the GRAPE data linearly, using the sediment/water interface and the first point where the GRAPE data could be correlated to the logging data as tie points. At Site 849 , logging data are of poor quality down to about $150 \mathrm{~m}$ because of unstable hole conditions (Fig. 2). At this site, no attempt was made to correlate the records on a fine scale above $150 \mathrm{~m}$, and we adjusted the GRAPE depths linearly.

\section{RESULTS}

Maps of GRAPE to log density for each of the five sites are presented in Figure 2, showing that density features match well after mapping. Tables (on CD-ROM, this volume) list depth-depth pairs for the transformations from mcd to logging depths at approximately $15 \mathrm{~cm}$ intervals for these five sites. Using these tables, other core data can be expressed on the logging depth scale, allowing direct comparisons with logging data.

An example of fine-tuning the depth scale over a short $(25 \mathrm{~m})$ $\mathrm{XCB}$-cored interval is shown in Figure 4. Figure 4A illustrates the initial match of a distorted signal to a reference signal. This figure shows composite depths basically reconciled to the log meters scale. Although major features match, correlations among small-scale features are poor. After inverse correlation, the smaller features also are well correlated (Fig. 4B). The correlation coefficient between logs and sediment over this depth interval improved from 0.31 (Fig. 4A) to 0.82 (Fig. 4B). Figure $4 \mathrm{C}$ shows the mapping function that translates mcd to logging depth over this $25-\mathrm{m}$ interval. The dashed line in Figure 4C shows the map of the GRAPE signal after a simple linear adjustment to fit the logging depth scale. Deviations of the map from the dashed line indicate the stretching and squeezing necessary to obtain the final correlation in Figure 4B. This mapping function is not highly nonlinear, nor does it have sharp discontinuities, yet there is a large improvement in correlation. The adjustments correct distortion of the cores relative to the logs.

This relative distortion between the two signals has several sources including (1) ship's heave (distortion of the logs), (2) hole rugosity, or roughness (distortion of the logs), (3) physical coring distortion (induced by the coring process), and (4) variations in the spliced density record relative to density recorded in the logged hole. This last source of distortion includes both coring distortion and local vari- 

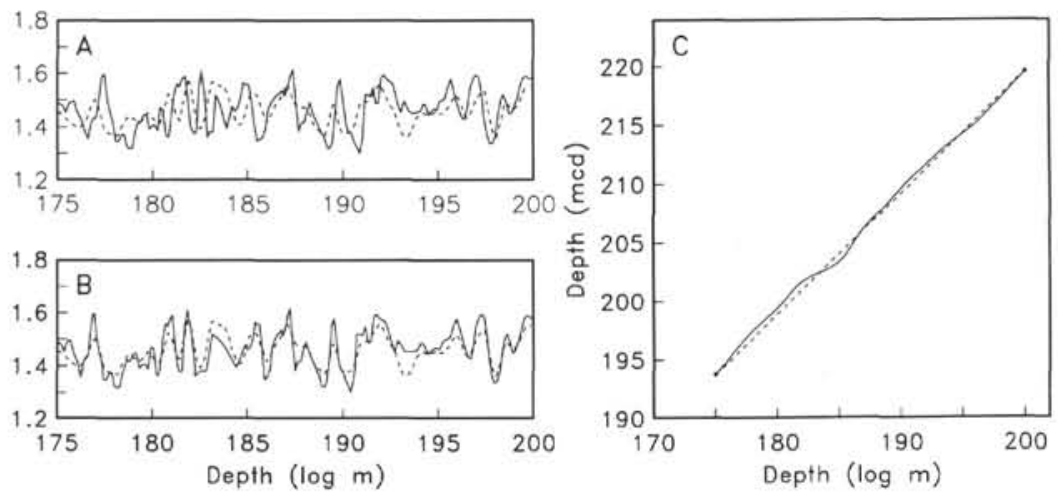

Figure 4. Example of nonlinear small-scale corrections to a short depth section from Site 847. A. Smoothed GRAPE (solid line) and logging (dashed line) data before fine-scale tuning, but after a first approximation. B. The same segment after fine-scale tuning. The dashed reference signal (log) is the same in both A and B. Fifteen coefficients were used to achieve this match, improving the correlation from 0.31 (A) to 0.82 (B). C. Mapping function describing the transformation of this segment from mcd to log meters. Dashed line represents the mapping function for a linear transformation. Solid line is the true map.

ability in sedimentation. We have no way of quantifying differences resulting from local sedimentation variability or coring artifacts. Hole B was logged at all five sites; therefore, the last source of distortion is applicable over intervals where the splice is not the density record from Hole B.

Table 1 shows the correlation coefficients over long depth sections $(100-200 \mathrm{~m})$ before and after small-scale refinement, and the average number of coefficients used in the mapping functions. Improvements in correlation coefficient range from 0.03 to 0.38 , with final correlations ranging from 0.78 at Site 850 to 0.93 at Site 846 . The average correlation between GRAPE and density logs for the five sites is 0.84 after mapping. Improvements in the correlation coefficients over shorter segments can be much higher (as over the $25 \mathrm{~m}$ section shown in Fig. 4).

\section{DISCUSSION}

The resulting depth-scale transformations between med and logging depths allow us to compare GRAPE and logging density signals directly in common depth and time domains. Comparison of sediment density to logging density allows one to determine to what extent logging estimates smooth true density variations of a sedimentary section. We made this comparison by examining the variance of logging density relative to GRAPE density using frequency-domain analyses. In addition, we examined how logging vs. GRAPE density measurements vary as a function of sedimentation rate.

\section{Depth-scale Comparisons}

Variations in the smoothed GRAPE and logging records were compared as a function of wavelength using spectral and cross-spectral analyses. These comparisons are given for each site in Figure 5. The two spectra are highly coherent over all wavelengths longer than 80 to $100 \mathrm{~cm}$, meaning that the data can be well correlated to a frequency resolution of 1.0 to 1.4 cycles $/ \mathrm{m}$, the point at which coherency falls below the 0.80 confidence level (Fig. 5). Scattered peaks in coherency above the 0.80 confidence level that occur at frequencies higher than 2.0 cycles $/ \mathrm{m}$ (periods of less than $0.5 \mathrm{~m}$ ) (Fig. 5) are not significant, because the HLDT smooths the record to modify essentially all signal at wavelengths less than $0.5 \mathrm{~m}$.

This level of resolution indicates that features at wavelengths shorter than about $80 \mathrm{~cm}$ cannot be resolved between core and logging data. If the dominant wavelength of the density variability at a site is
Table 1. Correlation coefficients between GRAPE and logging data before and after mapping and the average number of Fourier coefficients used.

\begin{tabular}{|c|c|c|c|c|}
\hline \multirow[b]{2}{*}{ Site } & \multirow{2}{*}{$\begin{array}{l}\text { Depth } \\
(\log \mathrm{m})\end{array}$} & \multicolumn{2}{|c|}{ Correlation } & \multirow{2}{*}{$\begin{array}{c}\text { Average number } \\
\text { of Fourier } \\
\text { coefficients }\end{array}$} \\
\hline & & Before & After & \\
\hline 846 & $75-230$ & 0.67 & 0.93 & 15.0 \\
\hline 846 & $244-340$ & 0.83 & 0.86 & 12.3 \\
\hline 847 & $64-231$ & 0.44 & 0.82 & 8.7 \\
\hline 849 & $149-335$ & 0.70 & 0.85 & 13.8 \\
\hline 850 & $70-206$ & 0.47 & 0.78 & 12.6 \\
\hline 850 & $206-346$ & 0.79 & 0.86 & 13.7 \\
\hline 851 & $74-253$ & 0.52 & 0.80 & 11.2 \\
\hline
\end{tabular}

longer than about $80 \mathrm{~cm}$, it should be possible to resolve coring gaps between successive cores using logging records. Detection of coring gaps using logging data depends on the size of the gap relative to the amplitude and frequency character of the primary density signal, which may not be predictable or constant. No gaps could be detected if the dominant wavelength of the density signal were less than $80 \mathrm{~cm}$, or if the dominant wavelength were equal to the gap size. However, gaps could be detected under one of two possible scenarios:

1. If the dominant period were long relative to the gap size, a kink or discontinuity in the distorted signal (here, the GRAPE data) could be diagnostic of a gap. In this case, gaps would become undetectable as the period approaches infinity, which in practice might be on the order of a ten meter period.

2. If the dominant period of a broadband signal were short relative to the gap size, cycles would be missing from the distorted signal indicating a gap. In this case, placement of the gap in depth would be possible only if the density signal on either side of the gap were of distinct enough broadband character (at wavelengths longer than $80 \mathrm{~cm}$ ) to be correlated to the logging record.

For example, if the dominant period of the sediment density signal were $1 \mathrm{~m} /$ cycle, a $1 \mathrm{~m}$ gap would not be detected. However, a $1-\mathrm{m}$ gap might be resolved if the dominant density period were $5 \mathrm{~m} /$ cycle (first scenario), or a 5-m gap might be detected if the dominant period of a broadband signal were $1 \mathrm{~m} /$ cycle (second scenario).

The average size gap between Leg 138 cores is about $1 \mathrm{~m}$ (Hagelberg et al., 1992). In practice, detection of coring gaps of this order is 

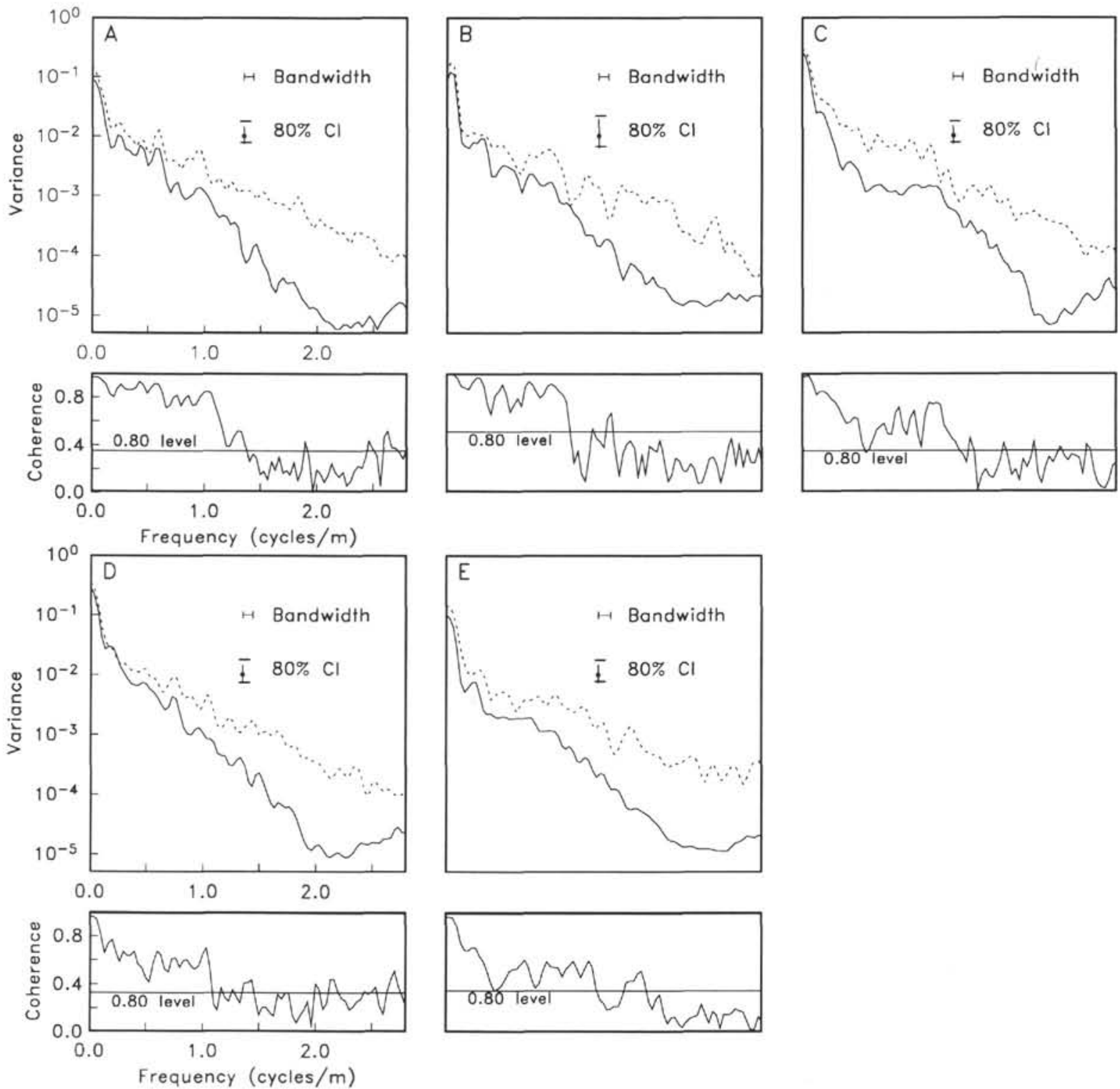

Figure 5. Cross-spectra of GRAPE and log variance in the depth domain and coherence plots for each of the five sites. Dashed curves are spectra from smoothed GRAPE; solid curves are spectra from logs. Spectral estimates were made using Blackman-Tukey methods from Jenkins and Watts (1968). A. Site 846, 75-225 m. B. Site 847, 64-135 m. C. Site 849, 150-300 m. D. Site 850, 70-240 m. E. Site 851, 74-195 $\mathrm{m}$. In all five coherence plots, coherence drops below the 0.80 level between 1.0 and $1.4 \mathrm{cycles} / \mathrm{m}$ frequency, meaning that the two signals are well correlated down to this depth resolution.

difficult. The uncertainty surrounding the detection and placement of gaps using the logging data implies that accurate composite records cannot be reliably constructed by mapping core data from only one hole into the logging record.

The variance spectra in Figure 5 also indicate that logging data have less variance than GRAPE data at all comparable frequencies. Some of the reduced variance in the logs relative to GRAPE results from smoothing in the sampling window of the HLDT. We quantified this difference by calculating gain as a function of frequency using techniques from Jenkins and Watts (1968). The gain spectrum $[H(f)]$ is calculated as the ratio of the cross-spectrum between GRAPE and logging data $\left[C_{12}(f)\right]$ to the GRAPE autospectrum $\left[C_{11}(f)\right]$ described by:

$$
H(f)=\frac{C_{12}(f)}{C_{11}(f)},
$$

after Jenkins and Watts (1968). Where GRAPE and logs are coherent, this frequency-dependent estimate indicates how strongly the log sig$\mathrm{nal}$ is amplified or attenuated relative to the sediment signal. A gain of greater than 1.0 indicates that the log signal is amplified relative to sediment density estimates. A gain of less than 1.0 indicates that $\log$ density estimates are attenuated relative to the sediment. The gain of the HLDT (Fig. 6) indicates that attenuation of the density signal by the logging tool gradually increases with frequency at most of the five sites. In general, $90 \%$ of the signal has been attenuated above frequencies of about 1.5 cycles $/ \mathrm{m}$.

There is no reason to expect the HLDT gain spectrum to vary significantly among sites. However, the gain spectrum for Site 849 is unusual, decreasing rapidly between 0.0 and $0.6 \mathrm{cycles} / \mathrm{m}$ frequency. The logging problem documented in the upper section of Site 849 (Fig. 2) may be indicative of a density log problem at this site, otherwise, it is unclear why Site 849 should be anomalous. Site 851 also 

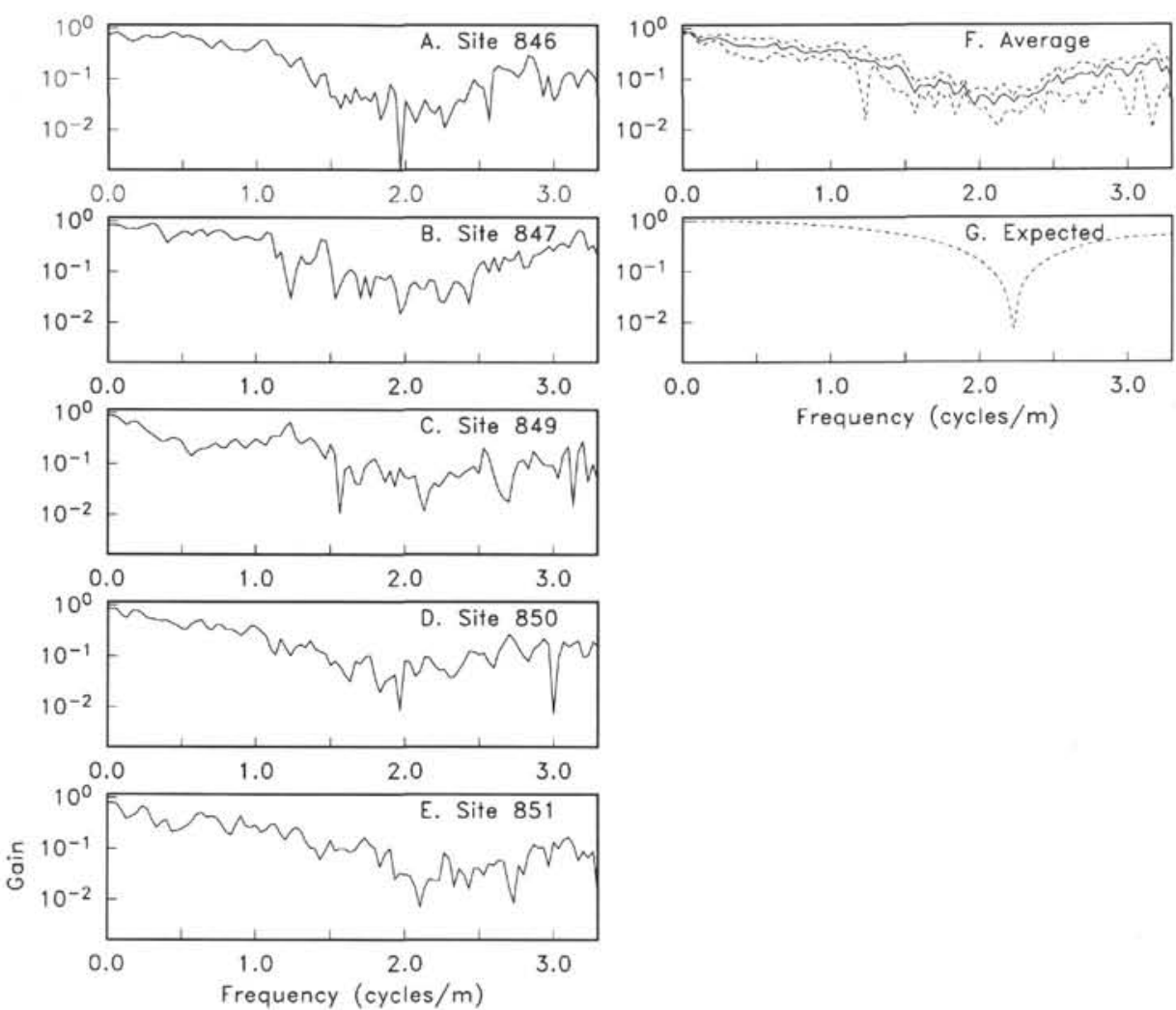

Figure 6. A-E. The gain spectrum of the HLDT at each site. Gain was calculated following Jenkins and Watts (1968). At Sites $846,847,850$, and 851 , gain decreases gradually with increasing frequency. Site 849 shows an anomalous gain spectrum which decreases rapidly between 0.0 and $0.6 \mathrm{cycles} / \mathrm{m}$. F. Average gain spectrum from all sites. Dashed lines represent standard deviation from the average gain function. G. Theoretical gain spectrum calculated as the ratio of the cross-spectrum between 3-point boxcar-filtered white noise and Gaussian-filtered white noise to the auto-spectrum of Gaussian-filtered white noise. Given the smoothing of the GRAPE (Gaussian-filtered) and logging data (boxcar-filtered), this gain spectrum would be expected. Estimated gain functions for $\mathrm{A}-\mathrm{F}$ are given in Table 2.

demonstrates decline in gain at low frequencies, although this is not as dramatic as that at Site 849 .

Best-fit linear equations for the HLDT gain were estimated for each site in order to arrive at a rough analytical approximation for the HLDT gain function (Table 2). A simplified linear equation for the average gain of the HLDT logging tool was empirically determined by an average of the least-squares fits of gain functions from all sites (Table 2). The average gain of the HLDT is

$$
G(f)=-2.37 \cdot f+0.68,
$$

where $G$ is gain, and $f$ is frequency. Note that the five gain functions fall roughly into two groups (Table 2). Functions from Sites 846, 847, and 850 have higher slopes and intercepts than functions from Sites 849 and 851 . The average function of the first group shows the least attenuation of logs relative to the sediment. The average gain of the HLDT from these sites is represented by:

$$
G(f)=-2.76 \cdot f+0.77 \text {. }
$$

Note that in both equations, the intercept of this function is less than one. In comparison, the gain spectrum for a boxcar filter that averages over three samples at $15-\mathrm{cm}$ intervals approaches one at the intercept and decreases to near zero at the frequency corresponding to one cycle per window (Fig. 6G). This hypothetical gain spectrum represents the expected gain of the logging tool, given its smoothing window and the smoothing of the GRAPE data.
Greater attenuation is indicated by the calculated average gain spectrum (Fig. 6F) than by the gain spectrum of the boxcar filter (Fig. $6 \mathrm{G})$. This situation may indicate either enhanced noise in the GRAPE measurements or sources of attenuation in the logging tool that are not explained simply by the tool's sampling window. A possible additional source of attenuation of the logging tool is hole rugosity, or roughness. Rugosity may inhibit contact of the HLDT with the hole wall, leading to measurements that are lower than true density. The logging density data at these sites do yield slightly lower average values than the GRAPE data. Caliper data for these logging runs indicate that the caliper was not always in contact with the hole wall (Fig. 7), suggesting that the pads of the HLDT were not always in contact with the formation. Sections over which the caliper data are constant for several meters (most notably at Site 847), are sections over which contact between the tool and the hole wall is suspect. Hole rugosity may be a significant factor contributing to log attenuation (D. Ellis, pers. comm., 1993).

Although the logs are significantly attenuated even at periods longer than would be expected from the HLDT window, the high coherency between the two records at long periods (greater than 80 -cm wavelengths) strongly suggests that logging data can be used as a lower-resolution proxy for GRAPE density in zones of poor recovery, such as the large coring gap from 230 to $245 \mathrm{~m}$ in Site 846 (Fig. 2). Using the average gain function above, one can scale the logging data to provide a comparable estimate of density variability over intervals of little or no recovery. This technique of filling coring gaps with logging data is limited to periods greater than $80 \mathrm{~cm} /$ cycle. 


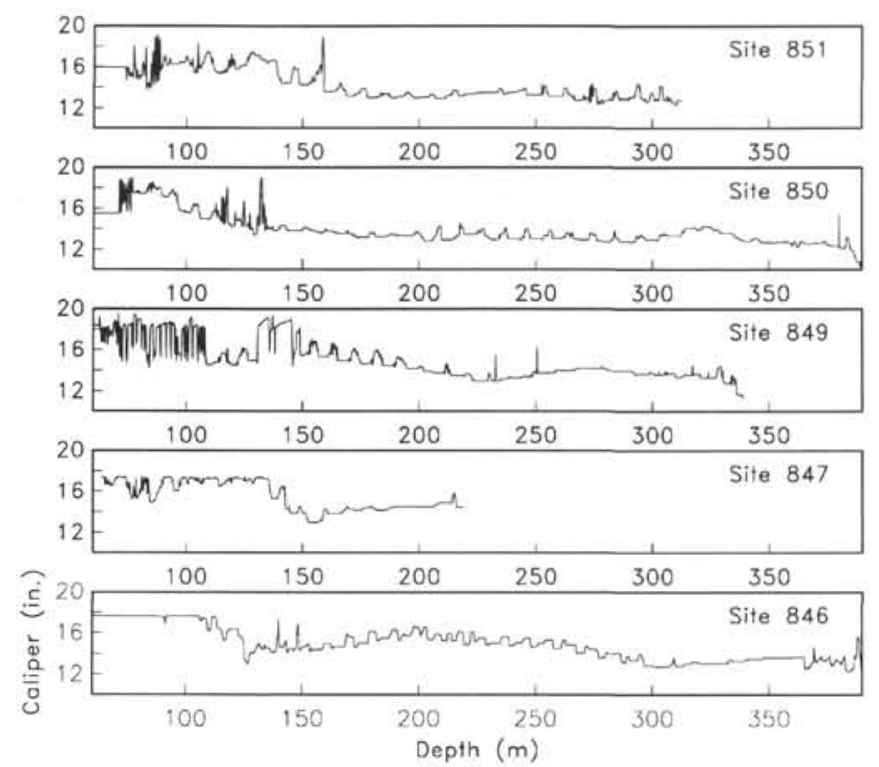

Figure 7. Caliper data from each of the five sites. Sections over which the caliper data are constant for several meters indicate where the caliper may not have been in contact with the hole wall, which suggests that the logging tool was not always in contact with the formation. Attenuation of the logs relative to the GRAPE may be partially the result of hole roughness.

Table 2. Slope, intercept, and correlation coefficients for estimated linear gain functions.

\begin{tabular}{cccc}
\hline Site & Slope & $\gamma$-intercept & $\begin{array}{c}\text { Correlation } \\
\text { coefficient }\end{array}$ \\
\hline 846 & $-2.91 \pm 0.14$ & $0.81 \pm 0.02$ & 0.89 \\
847 & $-2.86 \pm 0.16$ & $0.82 \pm 0.03$ & 0.84 \\
849 & $-1.74 \pm 0.21$ & $0.55 \pm 0.04$ & 0.54 \\
850 & $-2.52 \pm 0.12$ & $0.68 \pm 0.02$ & 0.88 \\
851 & $-1.81 \pm 0.15$ & $0.54 \pm 0.03$ & 0.72 \\
Average of all sites & $-2.37 \pm 0.08$ & $0.68 \pm 0.01$ & 0.73 \\
Average of 846.847 .850 & $-2.76 \pm 0.09$ & $0.77 \pm 0.02$ & 0.85 \\
\hline
\end{tabular}

Trying to adjust gain in the logging records to match GRAPE variability at higher frequencies would amplify analytical noise.

\section{Sedimentation Rates and Variance}

We calculated sedimentation rates based on both GRAPE and log data at 0.5-m.y. intervals (Fig. 8, Table 3), using Shackleton et al.'s orbitally tuned time scale (this volume). This time scale was developed by using magnetostratigraphy, biostratigraphy, and oxygen isotope data, and by making additional refinements by calibrating highresolution GRAPE data with orbital insolation cycles. For a given interval, sedimentation rates based on the mcd scale are usually higher than rates based on logging depths (Fig. 8). This difference is expected because the composite GRAPE records are longer than logging records, a fact that can have important implications when calculating mass accumulation rates. In cases where the splice and the log do not differ much in total length, the two sedimentation rates are similar for a given time interval. For example, Site 850 was not multiple-cored below 75 mbsf, which is the entire record shown in Figure 2. At this site, GRAPE and logging records are of similar length, which is an artifact of expansion of the cored section compensated by incomplete recovery from a single hole. Here, sedimentation rates calculated from mcd and $\log$ meters are close. Similarly, at Site 846, the multiple-
Table 3. GRAPE variance, logging variance, ratio of logging/GRAPE variance, sedimentation rate, and logging sedimentation rate for each site at $0.5-m . y$. increments.

\begin{tabular}{|c|c|c|c|c|c|c|}
\hline Site & $\begin{array}{l}\text { Age } \\
(\mathrm{Ma})\end{array}$ & A & B & C & D & $\mathrm{E}$ \\
\hline \multicolumn{7}{|l|}{846} \\
\hline & $2.5-3.0$ & 1.8910 & 0.9232 & 0.4882 & 47.97 & 42.48 \\
\hline & $3.0-3.5$ & 1.8320 & 0.7042 & 0.3844 & 38.74 & 34.46 \\
\hline & $3.5-4.0$ & 3.1560 & 2.3440 & 0.7427 & 34.02 & 30.46 \\
\hline & $4.0-4.5$ & 2.9570 & 1.9380 & 0.6554 & 32.48 & 26.26 \\
\hline & $4.5-5.0$ & 3.1190 & 2.1470 & 0.6884 & 45.08 & 39.42 \\
\hline & $5.0-5.5$ & 1.2830 & 0.5977 & 0.4659 & 41.00 & 34.74 \\
\hline & $5.5-6.0$ & 1.7190 & 1.0850 & 0.6312 & 55.74 & 47.68 \\
\hline & $6.0-6.5$ & 3.2800 & 1.5700 & 0.4787 & 43.92 & 33.40 \\
\hline & $7.0-7.5$ & 4.0200 & 1.5410 & 0.3833 & 38.12 & 38.84 \\
\hline & $7.5-8.0$ & 2.0850 & 0.8405 & 0.4031 & 19.74 & 21.58 \\
\hline & $8.0-8.5$ & 3.9510 & 1.6210 & 0.4103 & 13.64 & 11.44 \\
\hline & $8.5-9.0$ & 1.4690 & 0.9525 & 0.6484 & 17.46 & 17.56 \\
\hline & $9.0-9.5$ & 2.4390 & 1.3830 & 0.5670 & 16.78 & 17.82 \\
\hline & $9.5-10.0$ & 1.2730 & 0.2549 & 0.2002 & 14.52 & 13.76 \\
\hline \multicolumn{7}{|l|}{847} \\
\hline & $2.5-3.0$ & 1.5630 & 0.6343 & 0.4058 & 30.97 & 26.81 \\
\hline & $3.0-3.5$ & 1.7490 & 1.1600 & 0.6632 & 28.45 & 25.24 \\
\hline & $3.5-4.0$ & 2.2880 & 1.3300 & 0.5813 & 27.66 & 25.20 \\
\hline & $4.0-4.5$ & 3.1730 & 2.0210 & 0.6369 & 27.44 & 24.06 \\
\hline & $4.5-5.0$ & 8.0740 & 5.5900 & 0.6923 & 58.64 & 52.48 \\
\hline & $5.0-5.5$ & 4.8510 & 1.1490 & 0.2369 & 39.32 & 35.38 \\
\hline & $5.5-6.0$ & 7.2790 & 2.9200 & 0.4012 & 43.34 & 44.82 \\
\hline & $6.0-6.5$ & 4.0090 & 3.9470 & 0.9845 & 59.38 & 61.08 \\
\hline \multicolumn{7}{|l|}{849} \\
\hline & $5.5-6.0$ & 5.4940 & 2.5280 & 0.4601 & 72.68 & 66.82 \\
\hline & $6.0-6.5$ & 4.2270 & 2.5340 & 0.5995 & 68.72 & 62.28 \\
\hline & $6.5-7.0$ & 9.3940 & 7.1090 & 0.7568 & 62.54 & 59.90 \\
\hline & $7.0-7.5$ & 4.4890 & 2.1450 & 0.4778 & 36.42 & 34.16 \\
\hline & $7.5-8.0$ & 2.8840 & 1.6950 & 0.5877 & 19.96 & 19.80 \\
\hline & $8.0-8.5$ & 2.6720 & 0.6589 & 0.2466 & 27.24 & 24.38 \\
\hline & $8.5-9.0$ & 4.7430 & 2.1120 & 0.4453 & 18.82 & 15.74 \\
\hline & $9.0-9.5$ & 5.7790 & 4.1890 & 0.7249 & 18.68 & 16.14 \\
\hline & $9.5-10.0$ & 3.9550 & 4.7830 & 1.2094 & 13.90 & 13.00 \\
\hline \multicolumn{6}{|c|}{. } & 2234 \\
\hline & & 5.7880 & 4.8880 & 0.84 & 41.07 & 37.72 \\
\hline & $5.0-5.5$ & 2.2660 & 1.4440 & 0.6372 & 48.66 & 48.30 \\
\hline & $5.5-6.0$ & 4.1040 & 2.0950 & 0.5105 & 61.42 & 63.78 \\
\hline & $6.0-6.5$ & 3.1330 & 2.3800 & 0.7597 & 56.40 & 55.42 \\
\hline & $6.5-7.0$ & 9.4410 & 6.3050 & 0.6678 & 73.44 & 76,42 \\
\hline & $7.0-7.5$ & 2.1170 & 1.8940 & 0.8947 & 45.92 & 44.60 \\
\hline & $7.5-8.0$ & 2.3430 & 1.0410 & 0.4443 & 25.00 & 25.96 \\
\hline & $8,0-8.5$ & 1.6870 & 0.6579 & 0.3900 & 39.40 & 41.06 \\
\hline & $8.5-9.0$ & 1.9110 & 1.7270 & 0.9037 & 32.60 & 31.70 \\
\hline & $9.0-9.5$ & 1.5080 & 1.6800 & 1.1141 & 27.88 & 26.32 \\
\hline & $9.5-10.0$ & 2.1580 & 1.4050 & 0.6511 & 30.50 & 32.90 \\
\hline & $4.5-5.0$ & 2.4970 & 1.1610 & 0.4650 & 27.71 & 24.24 \\
\hline & $5.0-5.5$ & 1.9210 & 0.9258 & 0.4819 & 31.71 & 28.59 \\
\hline & $5.5-6.0$ & 1.8800 & 1.0040 & 0.5340 & 43.38 & 38.36 \\
\hline & $6.0-6.5$ & 2.3630 & 1.4740 & 0.6238 & 46.42 & 40.72 \\
\hline & $6.5-7.0$ & 5.4400 & 3.0070 & 0.5528 & 62.78 & 41.92 \\
\hline & $7.0-7.5$ & 1.5400 & 0.2772 & 0.1800 & 34.76 & 26.44 \\
\hline & $7.5-8.0$ & 1.5900 & 1.0420 & 0.6553 & 43.98 & 24.46 \\
\hline & $8.0-8.5$ & 1.4860 & 0.5069 & 0.3411 & 29.40 & 33.74 \\
\hline & $8.5-9.0$ & 2.3320 & 1.3110 & 0.5622 & 36.48 & 25.94 \\
\hline & $9.0-9.5$ & 2.1560 & 1.3780 & 0.6391 & 27.00 & 21.82 \\
\hline & $9.5-10.0$ & 1.8100 & 0.9388 & 0.5187 & 32.64 & 25.56 \\
\hline
\end{tabular}

Notes: $\mathrm{A}=$ GRAPE variance: $\mathrm{B}=$ logging variance: $\mathrm{C}=$ ratio of $\log$ ging/GRAPE variance; $\mathrm{D}=$ sedimentation rate $\left(\mathrm{m} / \mathrm{m} . \mathrm{y}_{\mathrm{.}}\right): \mathrm{E}=$ logging sedimentation rate (logging $\mathrm{m} / \mathrm{m} . \mathrm{y}$.).

cored section ends at $250 \mathrm{mbsf}$, at approximately $6.5 \mathrm{Ma}$. Previous to 6.5 Ma, GRAPE-based and log-based sedimentation rates are similar (Fig. 8). At all sites, the difference between med- and log-calculated sedimentation rates is not constant, indicating that the two density records are irregularly distorted relative to one another.

Given the form of the estimated gain function for the HLDT, we might expect the ratio of total variance measured by the log relative to the variance measured by the GRAPE to change as a function of sedimentation rate. From this expectation, we assume that density variability as a function of time is uniformly recorded at a given site and that the result of varying sedimentation rates is an expanded or contracted depth series. The sensitivity of the log to GRAPE variance ratio to sedimentation rates is controlled by the nature of the variance 

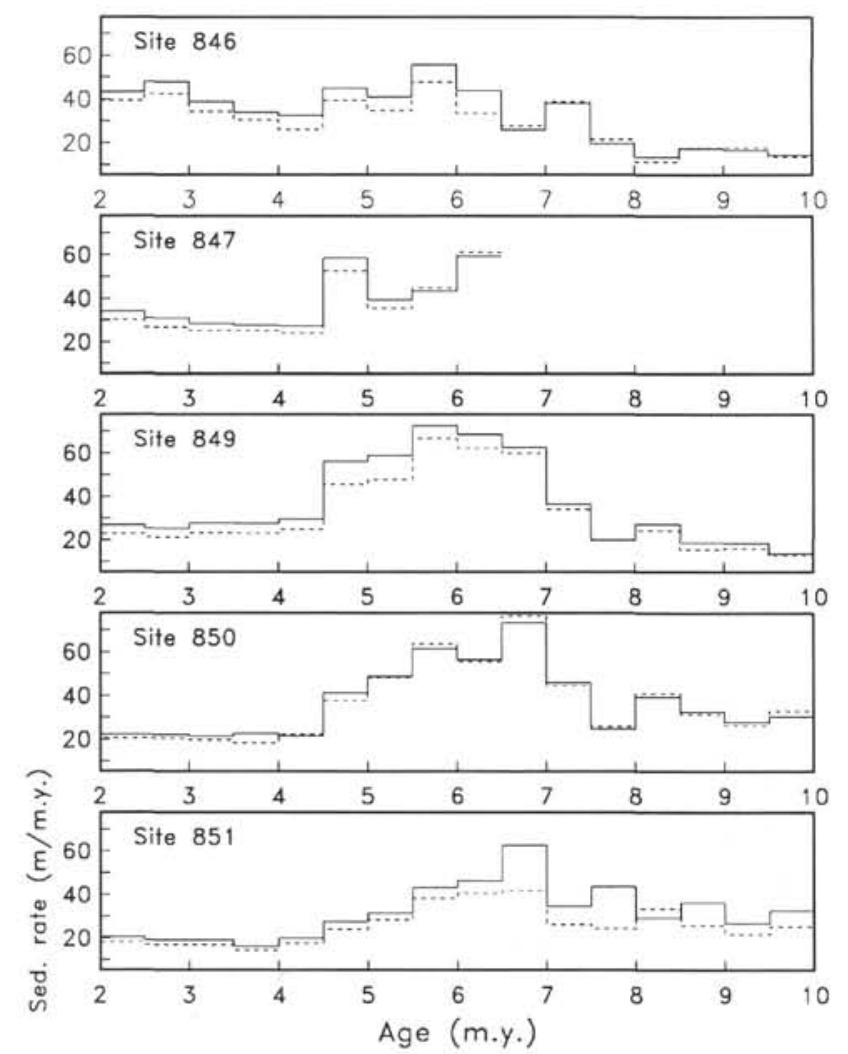

Figure 8. Comparisons of sedimentation rates based on mcd and logging meter depth scales in 0.5 m.y. intervals from Shackleton et al.'s orbitally tuned time scale (this volume) (Table 3). Solid lines represent mcd rates (GRAPE); dashed lines represent logging rates. Mcd-based sedimentation rates are typically higher than log-based sedimentation rates, except where the GRAPE record and logging record are of similar length, for example, in Site 850 and pre-6.5 Ma Site 846 .

spectra of the primary density signal. If the true variance spectra of sediment density are originally concentrated at low frequencies, changing sedimentation rates will have little effect on variance attenuation until sedimentation rates are sufficiently low so that much of the variance spectra is found at wavelengths greater than 1.5 cycles $/ \mathrm{m}$.

The total variance over $0.5-\mathrm{m}$.y. increments is greater for GRAPE data than for logging data (Fig. 9), which confirms this inference from the power spectra (Fig. 5). The ratio of log variance to GRAPE variance estimates the signal attenuation of the logs compared to the GRAPE, as does the gain spectrum. To determine whether a relationship exists between signal attenuation and sedimentation rates, we plotted the ratio of $\log$ to GRAPE variances at approximately $0.5-\mathrm{m}$.y. intervals as a function of sedimentation rate (Fig. 10). Ratios of log variance to GRAPE variance are not consistent (Table 3 ), nor does any apparent relationship exist between this ratio and the sedimentation rate (Fig. 10). This result indicates that total variance must be a function of factors other than sedimentation rate. Spatial and temporal variabilities in true sediment density may have a greater effect on variance in the logging record than do changes in sedimentation rate, and sedimentation rates may vary significantly within intervals of 0.5 m.y.

\section{Temporal Resolution of Logs}

Sedimentation rates limit the applicability of logging data to highresolution paleoclimatic studies. Time series spectra over intervals from Sites 846 and 847 (Fig. 11) indicate that density variations can be detected by the density log down to periods of $30 \mathrm{k}$.y. at these sites that have high sedimentation rates ( 30 to $50 \mathrm{~m} / \mathrm{m}$.y.). Thus, the density

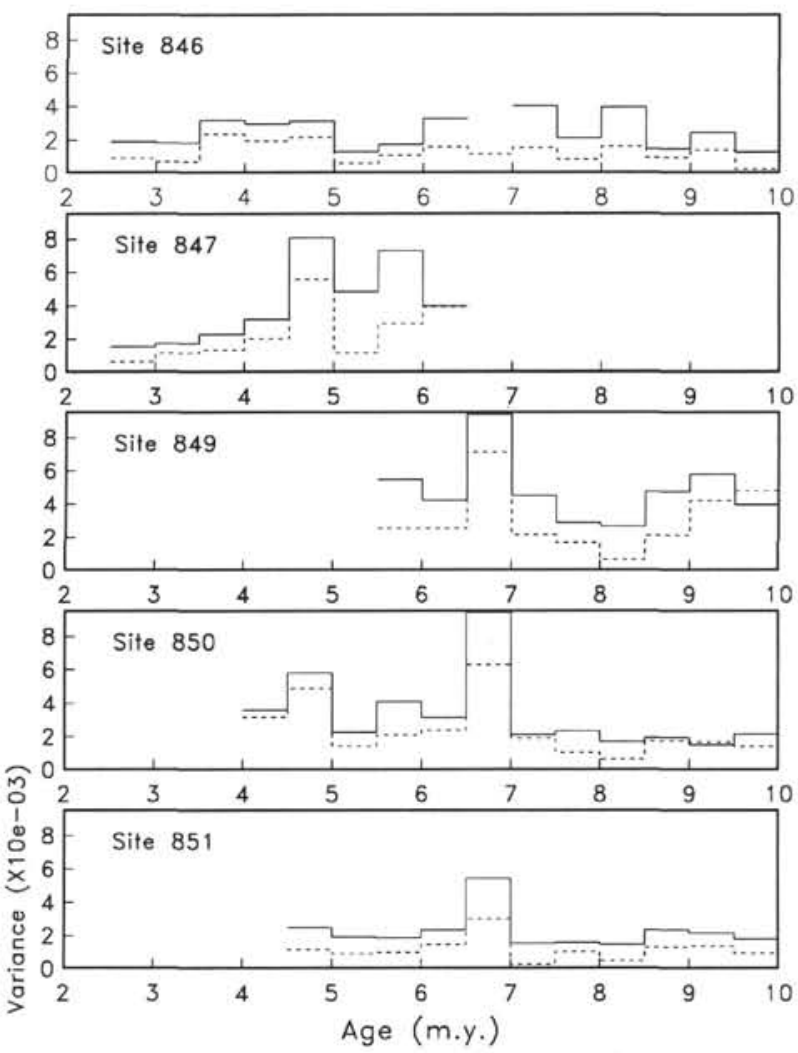

Figure 9. Comparisons of GRAPE and logging variances (Table 3) in 0.5-m.y. intervals from Shackleton et al.'s orbitally tuned time scale (this volume). Solid lines represent smoothed GRAPE variance, dashed lines represent logging variance. Logging records typically have lower variances than GRAPE records.

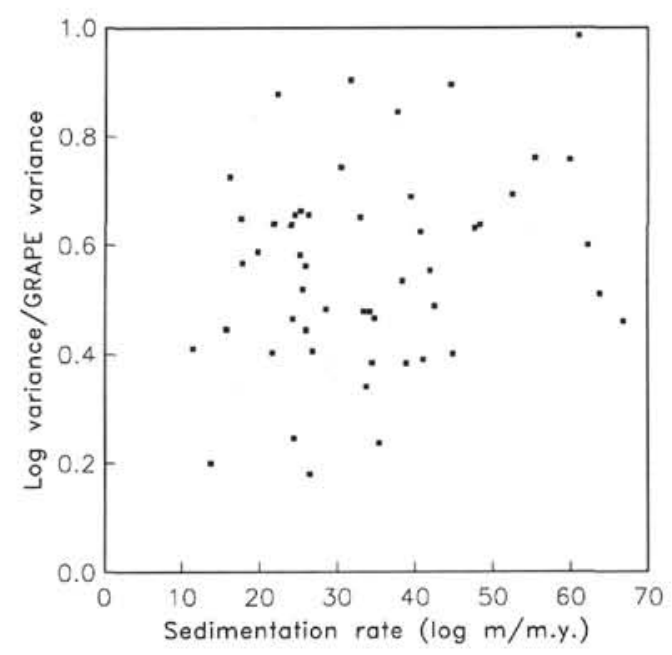

Figure 10. Ratio of logging variance to GRAPE variance as a function of log sedimentation rate for all five sites; no apparent relationship can be seen between the ratios and sedimentation rates.

logs at Leg 138 sites can record paleoclimatic changes at periodicities as short as the orbital period of obliquity (41 k.y.) and sometimes precession (23-19 k.y.), although attenuated relative to true density signals. The minimum sedimentation rate necessary to resolve precessional variations using the HLDT was estimated to be about $40 \mathrm{~m} / \mathrm{m}$.y. by deMenocal et al. (1992). In cores having lower sedimentation rates, logging density records are less useful for studies of orbital scale 

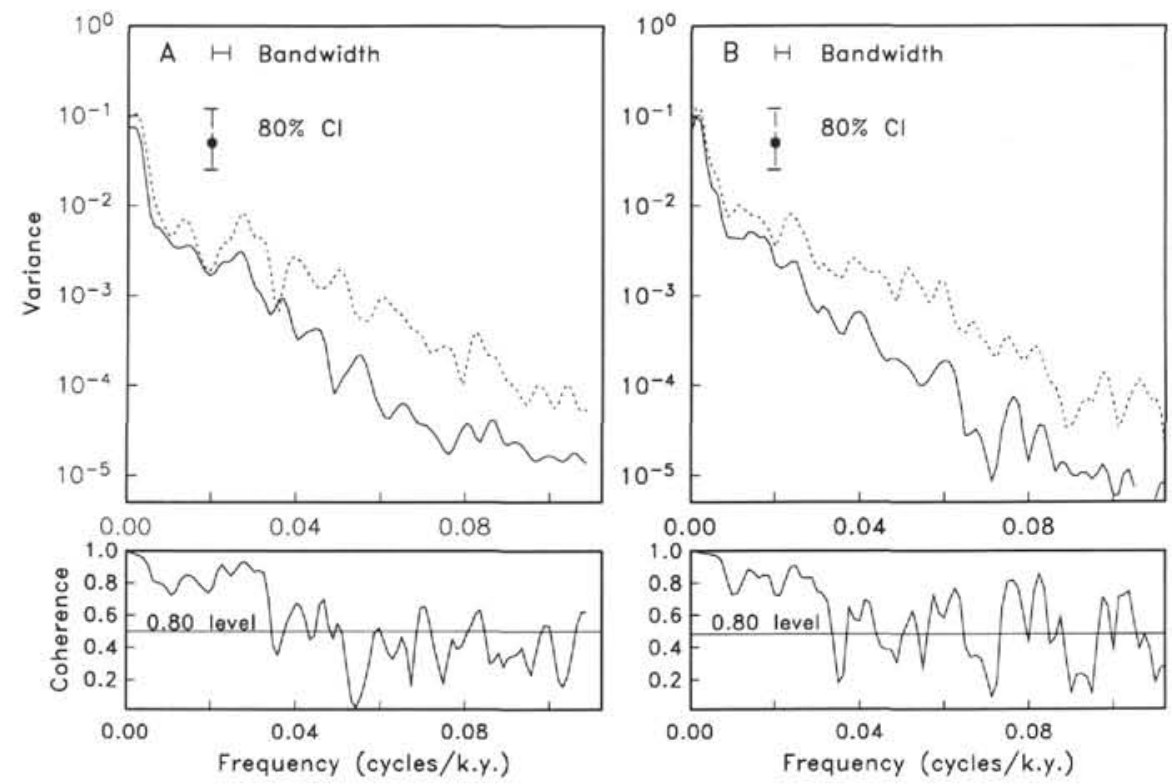

Figure 11. A. Time series spectrum, 2.4-4.0 Ma, Site 846. Sampling interval is 4.6 k.y. Notes as in Figure 5. B. Time series spectrum, $2.0-4.2 \mathrm{Ma}$, Site 847 . Sampling interval is $4.0 \mathrm{k} . \mathrm{y}$. Coherence in both A and B falls below the 0.80 level at $1 / 25$ to $1 / 30$ k.y. frequency.

variability because the HLDT's large sampling window $(50 \mathrm{~cm})$ averages high-frequency fluctuations.

\section{CONCLUSIONS}

We have defined depth scales for sedimentary sections recovered at five sites during Leg 138 by correlating GRAPE density measured on cores with density measured by downhole logs. Inverse correlation determined mapping functions for converting core data from the composite depth scale to a "true" depth scale that is consistent with the logging data.

This transformation improves calculations of sedimentation rates by assigning the most accurate depths to recovered sediments. It allows one to compare core data directly with logging data from Leg 138 and also facilitates correlation to older drill sites that have no composite depth sections. The resulting depth scale transformations (CD-ROM, this volume) are applied easily to other data sets at the same sites within the resolution limitation of about $15 \mathrm{~cm}$.

The internally consistent depth scale was used to compare sediment and logging density measurements directly. The GRAPE and logging density records are coherent at wavelengths longer than 80 $\mathrm{cm}$. Gain spectra of the HLDT demonstrate attenuation of logging density estimates at every frequency. Logging data can be used to fill gaps in core records where recovery is poor or when continuous cores are unavailable, but only if a frequency-dependent gain function is used to adjust the variance distribution in the logging data to match that of the GRAPE data. Detecting coring gaps using logging data is difficult in practice and depends on the nature of the primary density signal relative to the gap size.

Density logs from sites having high sedimentation rates $(>40$ $\mathrm{m} / \mathrm{m}$.y.) record lithologic variations at orbital frequencies $(20-100$ cycles/k.y.). After mapping core depths to logging depths, age models developed for the cores can be applied to the logs, which enhances the usefulness of all the borehole data for paleoclimatic studies.

\section{ACKNOWLEDGMENTS}

Thanks to reviewers Tom Janecek and David Mosher and to Larry Mayer for helpful comments. Darwin Ellis and Cristina Broglia were helpful in providing information about the density logs.

\section{REFERENCES}

Alexandrovich, J.M., and Hays, J.D., 1989. High-resolution stratigraphic correlation of ODP Leg 111 Holes 677 A and 677B and DSDP Leg 69 Hole 504. In Becker, K., Sakai, H., et al., Proc. ODP, Sci. Results, 111: College Station, TX (Ocean Drilling Program), 263-276.

Bloemendal, J., Tauxe, L., Valet, J.-P., and Shipboard Scientific Party, 1988. High-resolution, whole-core magnetic susceptibility logs from Leg 108. In Ruddiman, W., Sarnthein, M., Baldauf, J., et al., Proc. ODP, Init. Repts., 108: College Station, TX (Ocean Drilling Program), 1005-1013.

Boyce, R.E., 1976. Definitions and laboratory techniques of compressional sound velocity parameters and wet-water content, wet-bulk density, and porosity parameters by gravimetric and gamma ray attenuation techniques. In Schlanger, S.O., Jackson, E.D., et al., Init. Repts. DSDP, 33: Washington (U.S. Govt. Printing Office), 931-958.

deMenocal, P., Bloemendal, J., and King, J., 1991. A rock-magnetic record of monsoonal dust deposition to the Arabian Sea: evidence for a shift in the mode of deposition at 2.4 Ma. In Prell, W.L., Niitsuma, N., et al., Proc. ODP, Sci. Results, 117: College Station, TX (Ocean Drilling Program), 389-407.

deMenocal, P.B., Bristow, J.F., and Stein, R., 1992. Paleoclimatic applications of downhole logs: Pliocene-Pleistocene results from Hole 798B, Sea of Japan. In Pisciotto, K.A., Ingle, J.C., Jr., von Breymann, M.T., Barron, J., et al.,Proc. ODP, Sci. Results, 127/128 (Pt. 1): College Station, TX (Ocean Drilling Program), 393-406.

Farrell, J.W., and Janecek, T.R., 1991. Late Neogene paleoceanography and paleoclimatology of the northeast Indian Ocean (Site 758). In Weissel, J., Peirce, J., Taylor, E., Alt, J., et al., Proc. ODP, Sci. Results, 121: College Station, TX (Ocean Drilling Program), 297-358.

Froelich, P.N., Malone, P.N., Hodell, D.A., Ciesielski, P.F., Warnke, D.A., Westall, F., Hailwood, E.A., Nobes, D.C., Fenner, J., Mienert, J., Mwenifumbo, C.J., and Müller, D.W., 1991. Biogenic opal and carbonate accumulation rates in the subantarctic South Atlantic: the late Neogene of Meteor Rise Site 704. In Ciesielski, P.F., Kristoffersen, Y., et al., Proc. ODP, Sci. Results, 114: College Station, TX (Ocean Drilling Program), 515-550.

Hagelberg, T., Shackleton, N., Pisias, N., and Shipboard Scientific Party, 1992. Development of composite depth sections for Sites 844 through 854 . In Mayer, L., Pisias, N., Janecek, T., et al., Proc. ODP, Init. Repts., 138 (Pt. 1): College Station, TX (Ocean Drilling Program), 79-85.

\footnotetext{
- Abbreviations for names of organizations and publication titles in ODP reference lists follow the style given in Chemical Abstracts Service Source Index (published by American Chemical Society).
} 
Heath, G.R., Rea, D.H., and Levi, S., 1985. Paleomagnetism and accumulation rates of sediments at Sites 576 and 578, Deep Sea Drilling Project Leg 86, western North Pacific. In Heath, G.R., Burckle, L.H., et al., Init. Repts. DSDP, 86: Washington (U.S. Govt. Printing Office), 459-502.

Jenkins, G.M., and Watts, D.G., 1968. Spectral Analysis and Its Applications: San Francisco (Holden Day).

Karlin, K., Ruddiman, W.F., and McIntyre, A., 1989. Comparison of late Pliocene and late Pleistocene sea-surface temperatures of the equatorial Atlantic divergence. In Ruddiman, W., Sarnthein, M., et al., Proc. $O D P$, Sci. Results, 108: College Station, TX (Ocean Drilling Program), 187-210.

Lyle, M., Mayer, L., Pisias, N., Hagelberg, T., Dadey, K., Bloomer, S., and the Shipboard Scientific Party of Leg 138, 1992. Downhole logging as a paleoceanographic tool on Ocean Drilling Program Leg 138: interface between high-resolution stratigraphy and regional syntheses. Paleoceanography, 7:691-700.

Martinson, D.G., Menke, W., and Stoffa, P.L., 1982. An inverse approach to signal correlation. J. Geophys. Res., 87:4807-4818.

Mayer, L., Pisias, N., Janecek, T., et al., 1992. Proc. ODP, Init. Repts., 138 (Pts. 1 and 2): College Station, TX (Ocean Drilling Program).

Murray, D.W., and Prell, W.L., 1991. Pliocene to Pleistocene variations in calcium carbonate, organic carbon, and opal on the Owen Ridge, Northern Arabian Sea. In Prell, W.L., Niitsuma, N., et al., Proc. ODP, Sci. Results, 117: College Station, TX (Ocean Drilling Program), 343-363.

Robinson, S.G., 1990. Applications for whole-core magnetic susceptibility measurements of deep-sea sediments: Leg 115 results. In Duncan, R.A., Backman, J., Peterson, L.C., et al., Proc. ODP, Sci. Results, 115: College Station, TX (Ocean Drilling Program), 737-771.
Ruddiman, W.F., Cameron, D., and Clement, B.M., 1987. Sediment disturbance and correlation of offset holes drilled with the hydraulic piston corer: Leg 94. In Ruddiman, W.F., Kidd, R.B., Thomas, E., et al. Init. Repts. DSDP, 94 (Pt. 2): Washington (U.S. Govt. Printing Office), 615-634.

Schlumberger, 1989. Log Interpretation Principles/Applications: Houston, TX (Schlumberger Educational Services).

Shackleton, N.J., Berger, A., and Peltier, W.R., 1990. An alternative astronomical calibration of the lower Pleistocene time scale based on ODP Site 677. Trans. R. Soc. Edinburgh, Earth Sci., 81:251-261.

Shackleton, N.J., and Hall, M.A., 1983. Stable isotope record of Hole 504 sediments: high-resolution record of the Pleistocene. In Cann, J.R., Langseth, M.G., Honnorez, J., Von Herzen, R.P., White, S.M., et al. Init. Repts. DSDP, 69:431-441.

1989. Stable isotope history of the Pleistocene at ODP Site 677. In Becker, K., Sakai, H., et al., Proc. ODP, Sci. Results, 111: College Station, TX (Ocean Drilling Program), 295-316.

Shackleton, N.J., and Shipboard Scientific Party, 1992. Sedimentation rates: toward a GRAPE density stratigraphy for Leg 138 carbonate sections. In Mayer, L., Pisias, N., Janecek, T., et al., Proc. ODP, Init. Repts., 138 (Pt. 1): College Station, TX (Ocean Drilling Program), 87-91.

Date of initial receipt: 5 February 1993

Date of acceptance: 3 January 1994

Ms 138SR-104 